\title{
EFICIÊNCIA DE SISTEMAS ALAGADOS CONSTRUÍDOS NA REMOÇÃO DE POLUENTES DE ÁGUAS RESIDUÁRIAS DA SUINOCULTURA
}

\author{
Viktor Kayro Souza Santos ${ }^{1}$ \\ Ana Paula Ferreira Colares ${ }^{2}$ \\ Rodrigo Nogueira Martins ${ }^{3}$ \\ Victória Viana Silva ${ }^{4}$ \\ Marco Aurélio Rodrigues de Souza ${ }^{5}$ \\ Danilo Pereira Ribeiro ${ }^{6}$
}

Resumo: O trabalho foi realizado com o objetivo de avaliar a remoção de poluentes do efluente da suinocultura em Sistemas Alagados Construídos (SACs) cultivados com as gramíneas Cynodon spp., híbrido Tifton-85, Paspalum vaginatum e Brachiaria mutica. Cada gramínea foi cultivada individualmente em um SAC de fluxo horizontal subsuperficial preenchidos com brita zero. O efluente utilizado passou pela biodigestão anaeróbia e posteriormente foi aplicado nos SACs com tempo de detenção hidráulica de 4 dias. Não houve significativa redução do $\mathrm{pH}$ ao longo do SAC. O tratamento de ARS por SACs cultivados com gramíneas pode aumentar a salinidade do efluente. O SAC cultivado com a gramínea Paspalum vaginatum foi mais eficiente na remoção de ST, SF, SV e DQO que as gramíneas Tifton 85 e Brachiaria mutica. Contudo, o efluente tratado no SAC cultivado com a Paspalum vaginatum apresentou as menores remoções de $N$ e $P$ em relação às outras duas gramíneas. Assim, o SAC cultivado com $P$. vaginatum propicia o efluente com melhor qualidade para a fertirrigação de culturas. Em nenhum dos SACs houve satisfatória remoção de $\mathrm{K}$ e $\mathrm{Na}$.

Palavras-chave: Efluente; Gramíneas; Wetlands.

\footnotetext{
${ }^{1}$ Engenharia Agrícola e Ambiental/Instituto Federal do Norte de Minas Gerais - IFNMG Campus Januária, Brasil. E-mail: viktorpel@hotmail.com.

2 Engenharia Agrícola e Ambiental/Instituto Federal do Norte de Minas Gerais - IFNMG Campus Januária, Brasil. E-mail: anapaula.colares@hotmail.com.

${ }^{3}$ Engenharia Agrícola e Ambiental/ Instituto Federal do Norte de Minas Gerais - IFNMG Campus Januária, Brasil. E-mail: rodrigonmartins@hotmail.com.

4 Engenharia Agrícola e Ambiental/ Instituto Federal do Norte de Minas Gerais - IFNMG Campus Januária, Brasil. E-mail: victoria.viana.s@gmail.com.

${ }^{5}$ Engenharia Agrícola e Ambiental/ Instituto Federal do Norte de Minas Gerais - IFNMG Campus Januária, Brasil. E-mail: marcoaurelio.rdesouza@yahoo.com.br.

${ }^{6}$ DSC Engenharia Agrícola, Instituto Federal do Norte de Minas Gerais - IFNMG Campus Januária, Brasil. E-mail: danilo.ribeiro@ifnmg.edu.br.
} 